\title{
Regimes of Patienthood: Developing an Intersectional Concept to Theorize Illness Experiences
}

\author{
KELLY ANN JOYCE \\ DREXEL UNIVERSITY \\ JENNIFER E. JAMES \\ UNIVERSITY OF CALIFORNIA, SAN FRANCISCO \\ MELANIE JESKE \\ UNIVERSITY OF CALIFORNIA, SAN FRANCISCO
}

\begin{abstract}
In this paper, we develop the concept regimes of patienthood. Regimes of patienthood highlights the micro and macro dimensions of illness, paying close attention to how the interplay between the two creates expectations and points of intervention for people when they are ill. Such expectations may vary across time, place, and social position (e.g., age, class, ethnicity, gender, race, sexuality). Regimes of patienthood are always regimes of power and resistance, where the forms of resistance may vary based on individuals' intersectional positions. We draw on two cases-a study of 45 mostly white, middle class adults living with autoimmune illnesses and a study of 20 Black women living with advanced cancer-to examine one dimension of regimes of patienthood-control. Although a number of social positions, such as age and race, co-produce illness experiences, we focus on three-class, insurance status, and gender-that are particularly salient in our data in relation to control. Such a move illustrates the theoretical power of regimes of patienthood for science and technology studies (STS).
\end{abstract}

\section{Keywords}

patienthood; medicine; illness; intersectionality

Kelly Ann Joyce, Email: kaj68@drexel.edu Jennifer E. James, Email: Jennifer.james@ucsf.edu Melanie Jeske, Email: Mel.jeske@ucsf.edu 


\section{Centering Patients in Science and Technology Studies Scholarship on Medicine}

STS scholars identify and analyze broad trends in medicine such as biological citizenship (Rabinow 1996; Rose 1996), biomedicalization (Clarke et al. 2003), the datafication of life (Neff and Nafus 2016; Schull 2016), pharmaceuticalization (Abraham 2010; Bell and Figert 2012; Dumit 2012), and surveillance medicine (Armstrong 1995; Lupton 2013a, b). In these literatures, scholars highlight changes in medical practice, examining, for example, the expansion of diagnostic categories and interventions into more areas of daily life. Although this work shows how the expectations of and for patients and clinicians shift in the wake of large-scale changes in medicine, typically it does not focus on people's lived experiences as patients or health care providers. Instead, these analyses importantly highlight transformations in the social patterns that structure medical care.

To bring people's situated experiences as patients into view, STS scholars initially turned to regimes of practice (Bell 2009; Klawiter 2008, 2004) and, more recently, patienthood (Erikainen et al. 2019; Kerr and Cunningham-Burley 2015; Sosnowy 2014; Vinson 2016). Regimes of practice conceptualizes how people's way of performing illness and treatment is situated within larger social structures (Bell 2009; Klawiter 2008, 2004). This concept, drawing on Foucauldian notions of power, highlights "regimes," that is, social systems of power and resistance, and "practices," that is, the content and form of medical care, knowledge creation, and dissemination, social movements, and policies and regulations. Although individuals are studied within regimes of practice, the concept decenters individuals by focusing on subjectivication in particular regimes, and by looking beyond patients in clinics to people as actors in their social and political worlds.

Patienthood draws on anthropology's use of the term personhood to describe how who counts as a person is constructed through social relations and varies across time and location (Appell-Warren 2014). Patienthood, like personhood, attends to the varied social processes that constitute how a person responds to illness as well as how a person might resist such practices and norms (Landzelius 2006). The inclusion of the word "patient" retains the analytical focus on individuals' situated experiences. Adding the word "hood" denaturalizes the word "patient," highlighting the identity's social construction and potential precariousness. Who counts as a patient? When? Where? And, what varieties of practices are differentially positioned patients expected to do?

\section{Advancing Regimes of Patienthood}

In this paper, we amplify and transform patienthood and regimes of practice to develop the concept regimes of patienthood. We take the conceptualization we proposed previously (Joyce and Jeske 2019) and advance it as an intersectional concept, one that makes power visible, highlights the centrality of science and technology, and addresses the structural dimensions of illness experiences. Intersectionality is an approach that highlights the interlocking of social positions such as race and class, demonstrating heterogeneity within groups and how numerous forms of oppression and privilege mutually construct one another (Collins and Bilge 2016; Crenshaw 1989; Grzanka 2014). Regimes of patienthood highlights the micro and macro dimensions of illness, paying close attention to how the interplay between the two creates expectations and points of 
intervention for people when they are ill. Such expectations may vary across time, place, and social position (e.g., age, class, ethnicity, gender, race, sexuality). Regimes of patienthood are always regimes of power and resistance, where the forms of resistance may vary based on an individual's intersectional position. In highly medicalized systems, people are always already patients, especially when participation in biomedicine is a prerequisite for participating in many aspects of society (e.g., school, work). The way individuals identify as patients (or not) is deeply tied to their other intersectional identities and impacts how patients form relationships with providers and their ability to enact control in regimes of patienthood.

Regimes of patienthood expands on the emergent use of regimes of practice and patienthood in the STS literature, engaging in a form of theorizing that builds on rather than dismisses previous theories (Roy 2018). Combining the two concepts ensures that the emphasis on the varied cultural construction of self (patienthood) and the focus on power and structure (regimes of practice) are integrated and foregrounded. Taking an intersectional approach makes visible the multiple dimensions of power, technoscientific practices, and structure in illness experiences.

In the section that follows, we examine one dimension of regimes of patienthoodcontrol— to explore the utility it offers to STS. We draw on two cases where we investigated illness experiences: a study of 45 mostly white, middle class adults living with autoimmune illnesses, and a study of 20 Black women living with advanced cancer. Although a number of social positions, such as age, race, religion, and sexuality, co-produce illness experiences, we focus on three-class, insurance status, and gender-that are particularly salient in our data and in relation to control.

\begin{tabular}{|c|c|c|c|c|c|c|c|c|}
\hline Study & $\begin{array}{l}\text { Sample } \\
\text { size }\end{array}$ & Gender & Race & $\begin{array}{l}\text { Age } \\
\text { range }\end{array}$ & Disease & Geographic & $\begin{array}{l}\text { Insurance } \\
\text { status }\end{array}$ & $\begin{array}{l}\text { Socioeconomic } \\
\text { Status (SES) }\end{array}$ \\
\hline James & 20 & $\begin{array}{l}20 \\
\text { women }\end{array}$ & 20 Black & $47-73$ & $\begin{array}{l}\text { Advanced } \\
\text { cancers }\end{array}$ & California & $\begin{array}{l}90 \% \\
\text { publicly } \\
\text { insured }\end{array}$ & $\begin{array}{l}15 \text { Low income, } \\
5 \text { middle - } \\
\text { upper middle }\end{array}$ \\
\hline $\begin{array}{l}\text { Joyce } \\
\text { \& Jeske }\end{array}$ & 45 & $\begin{array}{l}35 \\
\text { women } \\
10 \text { men }\end{array}$ & $\begin{array}{l}2 \text { Asian } \\
2 \text { Black } \\
1 \text { Latinx } \\
40 \text { white }\end{array}$ & $20-67$ & $\begin{array}{l}\text { Autoimmune } \\
\text { illnesses }\end{array}$ & $\begin{array}{l}\text { California } \\
\text { Pennsylvania } \\
\text { Virginia }\end{array}$ & $\begin{array}{l}90 \% \\
\text { privately } \\
\text { insured }\end{array}$ & $\begin{array}{l}\text { Middle - upper } \\
\text { middle }\end{array}$ \\
\hline
\end{tabular}

\section{Enacting Control in Technoscientific Regimes}

In our research, we found three areas where ideas about one's ability to control aspects of their lives in relation to illness are crucial: 1) making time to manage illness, 2) interactions with biomedicine, and 3) developing low-tech illness practices. In the study of autoimmune illnesses (Joyce and Jeske 2019), participants enacted a regime of patienthood that included researching their condition, developing a broad set of healing techniques, and putting themselves first, each of which took extensive amounts of time. Because of this, many took leave from employment, and others 
cut stressors in order to make space for practices such as rest and research, practices necessary to live well with illness. In part because of their middle-class status, participants had the agency to make such choices, even where there were financial ramifications. Their agency was further bolstered by the fact that most participants had health insurance, a social safety net that is not guaranteed in the US.

The investigation of Black women living with advanced cancer further demonstrates the role that class and insurance status plays in illness management (James 2016). For many, illness represents a loss of control that threatens the normalcy of daily life. Illness disrupts the lives of individuals who live in a state of economic precarity, and for whom securing basic needs is often outside their control, in class-specific ways. Unlike middle class patients, patients living in or near poverty are unable to cut key stressors-such as housing insecurity, surveillance by the police state, lack of personal safety-from their lives. In other words, making time and space is a more complex performance of patienthood that is impeded by structural barriers; in fact, for those living on the edge of economic security, illness can exacerbate existing stressors and present a further loss of control (James 2016; Shim 2010).

Another way patients enact control is through interactions with clinicians. In the study of autoimmune illness, participants emphasized the importance of finding "collaborative physicians" (Joyce and Jeske 2019). Collaborative physicians are ones who think outside of the box, employ modes of communication beyond face-to-face visits, and participate in partnerships where patients are seen as experts about their bodies. With illnesses marked by heterogeneity and unpredictability, such collaborations were perceived as crucial to preventing unplanned trips to hospitals and promoting one's ability to live their life. Participants living with advanced cancer who had private insurance also sought second opinions or clinical trials as a way to exert control. Yet, a patient's desire or ability to do this is related to their positionality. Many Black women living with advanced cancer described the importance of following their doctor's instructions; challenging their doctor, or in many cases collaborating with or asking questions, ran counter to their understanding of what constitutes a "good patient." Further, for patients who want to do so, it is risky to challenge physicians given the limitations on care. Patients with public insurance are constrained in terms of where they seek care and may not be able to switch doctors or institutions. In some cases, the only opportunity to perform control and manage their patienthood identity is to reject biomedicine (James 2016). Yet, people are unable to fully reject patienthood; even those who may reject particular biomedical interventions are still positioned as patients; they have entered the medical system by receiving a diagnosis, undergoing tests, and selectively choosing treatments.

Finally, in both studies, middle-class participants pursued low-tech techniques such as altering their diets to try to control the course of illness. Participants pursued new knowledge about "healthy" diets, supplement use, and potential triggers for their illnesses, and aimed to adjust their diet accordingly. These recommendations typically originated from non-medical sources. Making changes-in which patients may purchase "higher quality" food, add supplements/vitamins, or avoid certain foods-is a classed and gendered practice. One middle-class participant, who had to go onto public insurance and stopped working as a result of her cancer diagnosis, highlighted the 
prevalence of paying attention to diet as a health strategy. She also demonstrated how it is a classed practice when she described that a lack of resources made her unable to control her diet to her satisfaction, an inability she thought would put her health at further risk. As a classed, gendered activity, this mechanism of control again highlights patient positionality. Paying attention to diet is considered a gendered activity where women are expected to "know" such topics as part of performing gender; men who pursue dietary changes thus challenge such roles (Lorber and Moore 2002). Participants' use of foods and supplements varied and their discussion of these techniques to healthcare providers also varied. The ability of some patients to seek and talk with collaborative clinicians about the practices they develop outside biomedicine to manage their illnesses is an exercise of privilege. Control is thus a gendered and classed resource that is more and less accessible to participants based on their positionality.

Managing one's illness, through complying with providers' recommendations or changing aspects of their lives to promote wellness, is part of what it means to be a "good patient" in the current US healthcare system. This very expectation, though, is one in which positionality matters. Not everyone is able to "cut" things from some aspects of their lives or to add practices such as dietary changes when navigating illness. Both studies demonstrate how participants enact control within regimes of patienthood and variations among them. When a "good" patient is socially defined as one who complies with provider recommendations, reliably shows up for appointments, and is able to devote time to managing their illness, such expectations privilege middle-class ways of being and knowledge-practices often linked to women, potentially positioning other ways of doing illness as deviant."

It would be easy to assume that patients who do not seek to take control in these ways are not engaged patients. Such thinking ignores the structural forces at play. One's social location largely determines the control they have over many aspects of their life. Patients who have an expectation of control over safety, choice of doctors, and diet, and are able to take actions to attempt to reassert control over their illness, not only sit in a place of privilege but come to define normative expectations of patienthood. Examining this dimension of regimes of patienthood illuminates how expectations of patienthood co-produce inequalities. When individuals perform patienthood in particular ways, providers, caregivers, and even patients themselves may assign meaning to that performance in a manner that ignores the intersectional factors that shape how individuals' approach and manage illness.

In this paper we emphasized the intersection of class, insurance status, and gender as these were particularly salient when we combined our two sources of data. Yet, there are many meaningful social positions such as age, class, ethnicity, gender, race, religion, and/or sexuality that may be important in analyses of regimes of patienthood. The social categories chosen for an intersectional analysis will vary, depending on one's research questions and the key issues identified in one's data. Researchers need not always focus on the intersection of the same

4 Although we focus on how contemporary expectations for patients privilege middle-class ways of being, what is perceived as deviant behavior can be found in any social group. Privileged people may opt out of medical care, for example, and be perceived as deviant. However, the repercussions for behavior that is perceived as deviant may vary based on one's location in society (e.g., class, gender, race). 
categories (e.g., race, class, and gender), which may obscure other important and emergent intersections that matter for a particular study.

We encourage STS scholars to apply regimes of patienthood in a variety of contexts (e.g., locations, nations, and moments in time), paying attention to the structural components of care (e.g., health policies, cultural contexts) and individuals' experiences of illness. This paper highlighted control as a component of a regime of patienthood, yet other practices that comprise patienthood could be investigated. For example, what are people expected to do when ill? How and where do they take up these practices? Who counts as a medical expert? Whom do people consult when ill? What are the broader patterns in the expectations for and responses by patients? By focusing on patients' meaning making and action within relations of power and social structures, regimes of patienthood offers a theoretical tool to investigate how regimes of patienthood vary, as well as the social and political effects of this variance. Regimes of patienthood are always present, shaping biomedical interactions, even when they are not explicitly acknowledged.

\section{Acknowledgements}

We would like to thank Susan Bell, the ESTS editors Daniel Lee Kleinman and

Katie Vann, and the anonymous reviewer for their thoughtful comments and suggestions.

\section{Author Biography}

Kelly Joyce is a Professor of Sociology and the Center for Science, Technology

and Society at Drexel University. As a sociologist of science, medicine and technology, she investigates the social, political, and ethical dimensions of knowledge systems and expertise.

\section{Author Biography}

Jennifer E. James is an Assistant Professor in the Department of Social and Behavioral Sciences, the Institute for Health and Aging, and Bioethics at the University of California, San Francisco. She is a sociologist and Black Feminist scholar whose work lies at the intersection of race, gender, and health, focusing on the lived experience of chronic and potentially life-limiting illnesses.

\section{Author Biography}

Melanie Jeske is a doctoral candidate in sociology at the University of California, San Francisco. Her research examines the social, ethical, and political dimensions of emerging biomedical technologies, as well as the social structures that shape illness experience. 


\section{References}

Abraham, John. 2010. "Pharmaceuticalization of Society in Context: Theoretical, Empirical and Health Dimensions." Sociology 44(4): 603-622.

Appell-Warren, Laura. 2014. "Personhood": An Examination of the History and Use of an Anthropological Concept. Lewiston, NY: The Edwin Mellen Press.

Armstrong, David. 1995. "The Rise of Surveillance Medicine." Sociology of Health \& Illness 17(3): 393-404.

Bell, Susan and Ann Figert. 2012. "Medicalisation and Pharmaceuticalization at the Intersections: Looking Backward, Sideways and Forward." Social Science \& Medicine 75(5): 775-783. doi: 10.1016/0277-9536(96)00122-0.

Bell, Susan. 2009. DES Daughters: Embodied Knowledge and the Transformation of Women's Health Politics. Philadelphia, PA: Temple University Press.

Clarke, Adele, Janet Shim, Laura Mamo, Jennifer Fosket and Jennifer Fishman. 2003. "Biomedicalization: Technoscientific Transformations of Health, Illness, and U.S. Biomedicine." American Sociological Review 68(2):161-194.

Collins, Patricia Hill and Sirma Bilge. 2016. Intersectionality. 1 edition. Cambridge, UK; Malden, MA: Polity.

Crenshaw, Kimberlé Williams. 1989. "Demarginalizing the Intersection of Race and Sex: A Black Feminist Critique of Antidiscrimination Doctrine, Feminist Theory and Antiracist Politics." University of Chicago Legal Forum 1(8): 139-167.

Dumit, Joseph. 2012. Drugs for Life: How Pharmaceutical Companies Define Our Health. Durham, NC: Duke University Press.

Erikainen, Sonja, Martyn Pickersgill, Sarah Cunningham-Burley, and Sarah Chan. 2019. "Patienthood and Participation in the Digital Era." Digital Health 5:1-10. doi: $10.1177 / 2055207619845546$.

Grzanka, Patrick, editor. 2014. Intersectionality: A Foundations and Frontiers Reader. Boulder, CO: Westview Press.

Landzelius, Kyra. 2006. “Introduction: Patient Organization Movements and New Metamorphoses in Patienthood." Social Science \& Medicine 62(3): 529-37.

Lupton, Deborah. 2013a. "The Digitally Engaged Patient: Self-monitoring and Self-care in the Digital Health Era." Social Theory and Health 11(3): 256-270.

Lupton, D. 2013b. "Quantifying the Body: Monitoring and Measuring Health in the Age of mHealth Technologies." Critical Public Health 23(4): 393-403.

James, Jennifer E. 2016. "Black Women with Advanced Cancer and the Challenge of Biomedicine: A Black Feminist Methodological Exploration of the Lived Experience of Terminal Illness." PhD dissertation. Department of Social and Behavioral Sciences, University of California, San Francisco.

Joyce, Kelly and Melanie Jeske. 2019. "Revisiting the Sick Role: Performing Regimes of Patienthood in the 21" Century." Sociological Viewpoints 33(1): 70-90. doi:10.26908/3312019_016. 
Kerr, Anne and Sarah Cunningham-Burley. 2015. "Embodied Innovation and Regulation of Medical Technoscience: Transformations in Cancer Patienthood." Law, Innovation and Technology 7(2):187-205. doi: 10.1080/17579961.2015.1106103.

Klawiter, Maren. 2008. The Biopolitics of Cancer: Changing Cultures of Disease and Activism. Minneapolis, MN: University of Minnesota Press.

-------. 2004. "Breast Cancer in Two Regimes: The Impact of Social Movements on Illness Experience." Sociology of Health \& Illness 26(6):845-874. doi: 10.1111/j.14679566.2004.421_1.x.

Lorber, Judith and Lisa Jean Moore. 2002. Gender and the Social Construction of Illness, Second Edition. Lanham, MD: AltaMira Press.

Neff, G. and D. Nafus. 2016. Self-Tracking. Cambridge, MA: MIT Press.

Rabinow, Paul. 1996. Essays on the Anthropology of Reason. Princeton, NJ: Princeton University Press.

Rose, Nikolas. 1996. Inventing Our Selves: Psychology, Power and Personhood. Cambridge, New York \& Melbourne: Cambridge University Press.

Roy, Deboleena. 2018. Molecular Feminisms: Biology, Becomings, and Life in the Lab. Seattle, WA: University of Washington Press.

Schull, N. 2016. "Data for Life: Wearable Technology and the Design of Self-care." BioSocieties 11(3): 317-333.

Shim, Janet K. 2010. “Cultural Health Capital: A Theoretical Approach to Understanding Health Care Interactions and the Dynamics of Unequal Treatment." Journal of Health and Social Behavior 51(1):1-15. doi: 10.1177/ 0022146509361185.

Sosnowy, Collette. 2014. "Practicing Patienthood Online: Social Media, Chronic Illness, and Lay Expertise." Societies 4:316-329. doi:10.3390/ soc4020316.

Vinson, Alexandra. 2016. "'Constrained Collaboration': Patient Empowerment Discourse as Resource for Countervailing Power." Sociology of Health \& Illness 38(8): 1364-1378. 